the mountain." Even in these latter measurements we bave results in which the extreme variation is about 2000 feet, and this distance compared with 4 miles (about the height of the mountain) is a large quantity, and shows that a still more accurate determination must be made before its height is placed beyond doubt.
From the results of the measurements of the heights of these four mountains, the existing evidence seems to point to the "Star Mountain" of Mexico, the peak of Orizaba, with its 18,200 feet, as the culminating point of the North American continent.

\section{A NEW ELECTRIC LIGHT OTTO GAS-} ENGINE.

F LECTRIC lighting is becoming so universal in all parts at the present day, that we give an illustration of the latest form of gas-engine made by Crossley and Brothers,
Manchester. This engine, called the "High Speed Electric Light Otto Gas-Engine," runs at 250 revolutions, and is designed throughout to run at this exceptional speed. It is fitted with most of the latest improvements, such as Crossley's tube ignition, patent timing valve, and a special electric light governor, which makes it a very steady running engine for this kind of

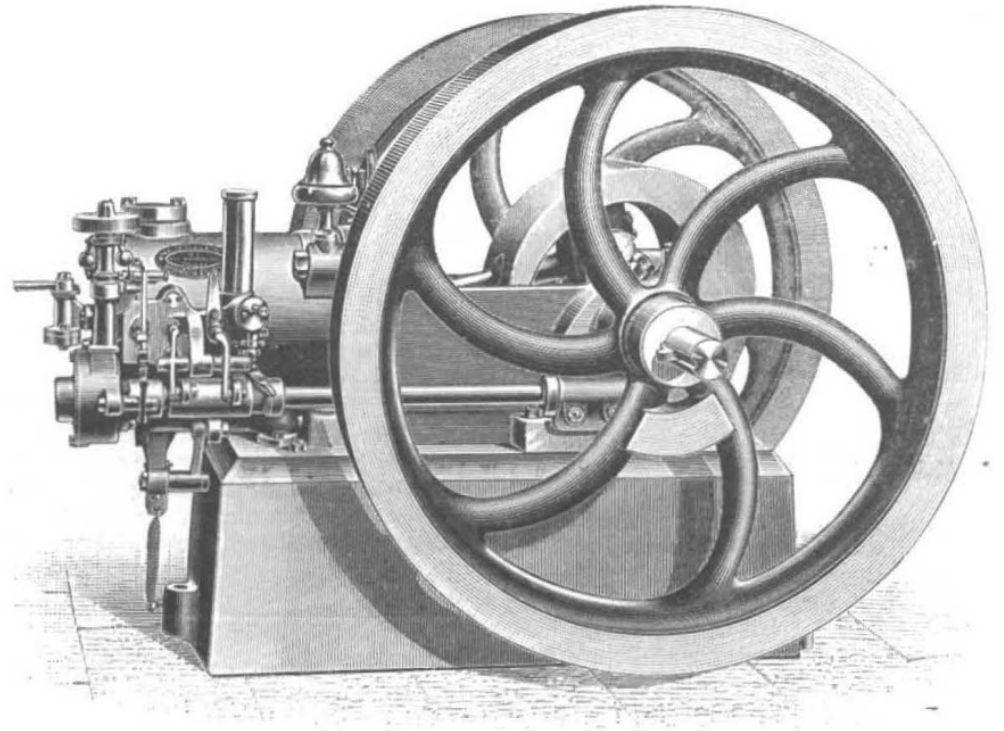

work. The makers claim that "electric light lamps can be driven direct from the dynamo without. fitting the dynamo with a flywheel or disc, as has hitherto been done when a small gas or steam-engine has been used; and that the light will be as absolutely steady as is possible with any form of motive power."

\section{SCIENTIFIC SERIALS.}

THE American Meteorological Fournal for September contains an article, by Prof. H. A. Hazen, on Espy's experiments on storm generation and the liberation of latent heat on cloudformation; these were made about 50 years ago, and Prof, Hazen states that they have never been checked, but have been accepted without question by meteorologists. His own experiments have led to different results, and he finds that deposition from moist air does not set free latent heat.-E. B. Garriott contributes an article on the origin of storms; he attributes their development to an excess of heat from the earth's surface by radiation, and their progressive movement to the precipitation of aqueous vapour at a considerable elevation, while the direction in which they move is regulated by the disposition of cold dry air found in areas of high pressure. For a verification of these facts, he points to the storms of the North American continent, a large majority of which originate over the great plateau region in the lee of the Pacific coast ranges of mountains, and advance towards the regions of greatest moisture which embrace the Great Lakes, the Gulf of Mexico, and the valleys of the principal rivers.-M. Faye has a supplementary article on trombes and tornadoes, for the purpose of introducing the figures illustrating his previous papers in the Tournal. - Mr. M. W. Harrington contributes an instructive paper on forests and soil temperatures. He has taken various sets of observations published in Germany and elsewhere, amounting altogether to I 50 years, and has discussed them by harmonic analysis for various periods, with the view of finding the distribution of temperatures in the soil within and out of the forest, at any depth, and at any time. The greatest difference between the forest soil and that of the open fields is at the surface, the mean difference of forest below open field being about $3^{\circ}$, but below the surface the differences between forest and open field do not progress uniformly. There appears to be a gain of heat in the upper soil of the woods which the open fields do not have.

American Fournal of Mathematics, vol. xiii,, No. I (Baltimore, October 189o). - The opening paper (pp. I-52), entitled " Ueber die zu der Curve $\lambda^{3} \mu+\mu^{3} \nu+\nu^{3} \lambda=0$ im projectiven Sinne gehörende mehrfache Ueberdeckung der Ebene," is by Mellen Woodman Haskell, a name not familiar to us, but belonging evidently to a mathematician of power, The discussion is exhaustive, and is fully illustrated with diagrams in the text, and two large-paged tables containing shaded diagrams. The reader who is familiar with Klein's "Ueber eine neue Art Riemann'scher Flächen" will easily follow the author's work. An index supplies the student with a ready key to the matters handled.-Prof. Cayley (pp. 53-58), in a note on a soluble quintic equation, discusses one of the equations given in Mr. Young's paper, "Soluble Quintic Equations with Commensurable Coefficients" (vol. x. pp. 99-130). The example considered is $x^{5}+3 x^{2}+2 x-1=0$, the solutions of which the author shows admit of being put in much simpler form than those given by Mr. Young.-Then there is an instalment of a course of lectures delivered at the Johns Hopkins University during the months of January and February 1889 , by Oskar Bolza. Its title is "On the Theory of Substitution-groups, and its Applications to Algebraic Equations." The paper is divided into two parts. The first develops the fundamental propositions, and concludes with a

NO. IO93, VOL. 42 ] 
short sketch of the extension of the theory to groups of operations in general. The second part deals with Galois's theory of algebraic equations, in particular their solution by radicals. The material is taken from Jordan, "Traité des Substitutions"; Serret, "Cours d'Algèbre Supérieure" ; and Netto, "Substitutionen-Theorie." Other authors have been consulted, and the whole has been strongly influenced by a course of lectures on the subject by Prof. Klein. The editor of the Fournal expresses a belief that this development will prove extremely useful to students. - This being the opening number of a new volume, is graced by a fine portrait of Prof. Cayley, which gives a very truthful presentment of this eminent mathematician's characteristic features.

IN the numbers of the Journal of Botany for August and September is an interesting mycological contribution from Dr. A. Barclay, describing some of the Ustilagineæ and Uredineæ parasitic on cereal crops and other crops in India. The most important of these are the following: Puccinia Sorghi on Sorghum vulgare, Melampsora Lini on Linum usitatissimum, Uromyces Pisi on Cicer arietinum and on Lathyrus sativus, Puccinia Fagopyri on Fagopyrum esculentum. Mr. W. H. Beeby contributes a paper on the British species of Sparganium; as regards fertilization, he states that they are rarely visited by insects; they are all proterogynous, and mostly wind-fertilized. Among the "Short Notes" is the very interesting record of the occurrence of the very rare Ranunculus ophioglossifolizs in Gloucestershire.

\section{SOCIETIES AND ACADEMIES. \\ PARIS.}

Academy of Sciences, September 29.-M. Duchartre in the chair. - On the theory of infectious disease, of recovery, of vaccination, and of natural immunity, by M. Ch. Bouchard.-On the absorption of carbon monoxide by rocks, by $M$. Berthelot. Observations in mines after explosions have been said to indicate that the rocks of which the walls are constituted possess a specific property by virtue of which they retain carbon monoxide in their pores for a longer period than other gases. From some experiments made to investigate this question, M. Berthelot finds that the volume of carbon monoxide absorbed by argillaceous rocks and given up by them, is sensibly identical with the volume of air absorbed and given up under the same conditions. Hence, rocks impregnated with carbon monoxide owing to an explosion do not retain it because of any specific action peculiar to this gas. - On acetylene condensed by the silent discharge, by the same author. An examination of the result of the condensation of acetylene by means of the silent discharge appears to indicate that it differs in character from that obtained by the influence of heat on the same compound.-Spark spectrum of gadolinium, by M. Lecoq de Boisbaudran. The author gives the wave-lengths of the lines, bands, and flutings characteristic of the spectrum of gadolinium.-On the atomic weight of terbium metals, by the same author. The value found from two experiments was I59:48. - On a new safetylamp for use in mines, by M. Charles Pollak. The lamp is an incandescent one. It weighs about 1800 grammes, and will give a light equal to 0.7 or 0.8 of a candle-power for twelve hours. Observations of Comets Coggia and Denning ( $b$ and $c$ 189o), made with the great equatorial of Bordeaux Observatory, by MM. G. Rayet, L. Picart, and Courty. Observations for position were made on July 27 and 29 and on August 6 in the case of the former comet, and on September 14 and 15 in the case of the latter.-Thermo-electric researches, by MM. Chassagny and $\mathrm{H}$. Abraham. The authors find, from some experiments, that the variation in the electromotive force produced by heating the poles of a copper-iron couple is practically constant between $0^{\circ}$ and $100^{\circ} \mathrm{C}$. It is therefore possible that thermo-electric elements may serve as standards of electromotive force better than electro-chemical cells. The same results were found with couples two months old as with those only two days old.-On a fungus of the Mucedinean group, by M. Raphael Blanchard.On the properties of the principal natural colouring-matters of yellow silk, and their similarity to those of carrotin, by M. Raphael Dubois. Evidence is adduced to show that raw yellow silk owes its colour to the presence of a substance analogous to

NO. IO93, VOL. 42] the colouring-matter recently extracted from the Diaptomus dentzcornis, by M. Blanchard, and considered as a carrotin of animal origin.-The identity in the structure of lightning and discharges from an induction machine, by M. E. L. Trouvelot.

\section{STOCKHolm.}

Royal Academy of Sciences, September 17.-On the discovery of cerium minerals and columbite, and on the occurrence of microlite, by Baron Nordenskiöld.-On the discovery of pinakiolite, trimerite, and centrolite, by G. Flink, communicated by Prof. Brögger.-On inclosures of dissimilar rocks in some Scandinavian diabases, by Herr H. Bäckström.-On maxima and minima by double integrals, by Dr. O. Kobb.-On a generalization of the Bernoullian functions, and their connection with the generalized series of Riemann, by Dr. A. Jonquière, of Basel.-Some formulæ of Bierens de Haan, by Dr. Lindman. -Études de la distribution spectrale de l'absorption dans le spectre infra-rouge, by Dr. K. Ångström.-On phenyl-totyl and benzylen-diamin, by Dr. Söderbaum and Prof. Widman.Derivatives of ortho-amido-benzyl-alcohol, iii., by Dr. Söderbaum. -Researches on the conductibility of the caloric in porous humid bodies, by Herr S. A. Andrée, C.E.-On the new edition of the collected works of Galileo, by Dr. G. Eneström.

\section{Amsterdam.}

Royal Academy of Sciences, September 27.-Prof. van de Sande Bakhuysen in the chair-Prof. Schoute dealt with some general theorems relating to directly similar plane figures. -Prof. Hubrecht described phases in the early development of the shrew's placenta, and called attention to the fact that, whereas in the hedgehog the uterine epithelium disappears-the subepithelial stroma forming the maternal contribution to the placenta-in the shrew, on the contrary, this contribution is directly derived from the epithelium of the uterus.

\section{CONTENTS.}

PAGE

A New Theory for the Sensitive Plant. By F. W. O. $56 \mathrm{r}$ Christy's "Birds of Essex" . . . . . . . . . . 564

Hypnotism. By Dr. A. T. Myers . . . . . . . 565 Our Book Shelf :-

Wright : "Text-book of Mechanics."-W.

Stewart: "An Elementary Text-book of Heat and Light."-W.

"The Confessions of a Poach"; * . 567

.... 567

"B " . . 567

"Blackie's Modern Cyclopædia." . . . . . . . . 567

Recent Classification of the Shrews.-Dr. R. W. Shufeldt . . . . . . . . . 567

Musical Sands.-Cecil Carus-Wilson $:{ }_{568}$

With what Four Weights (and a Pair of Scales) can be Weighed any Number of Pounds from I to 40 inclusive?-E, R, F

Protective Coloration of $\mathrm{Eggs}_{-} \mathrm{B}$. Titchener.

Lunar Photography. (Illustrated.) Richard A.

Gregory . . . . . . . . . 568

Comparative Palatability of Insects, \&c. By ${ }^{\circ}$. B.

Titchener and F. Finn . . . . . . . . 57

The Progress of Biology in Canada . . . . . . 572

Notes ... . . . . . . . 573

Our Astronomical Column:-

Objects for the Spectroscope.-A. Fowler . . . . . 576

Observations of Comets . . . . . . . . 576

Photographing Stars in the Daytime . . . . . . 576

Physics at the British Association . . . . . . . . . 576

Biology at the British Association . . . . . . 579

Geography at the British Association . . . . . . 579

Anthropology at the British Association . . . . . 580

The Volcanoes of the Table-land of Mexico. . . 582

A New Electric Light Otto Gas-Engine. (Illius-

trated.) ............ . 583

Scientific Serials . . . . . . . . . . . 583

Societies and Academies . . . . . . . 584 